\title{
Study on Predicting Sustainable Growth Level of the city
}

\author{
Shaohui Jin ${ }^{1, a}$ \\ ${ }^{1}$ North China Electric Power University(Baoding), Baoding 071000, China \\ a1393543628@qq.com
}

\begin{abstract}
We choose a city named Zurich and establish a city sustainable development evaluation index system with economic status, social status and ecological environment. First, we analyze the city's current situation, and draw up a new plan for it. Also, we get four sustainable growth levels: Excellent, Good, Moderate, Bad. Then, We establish a Gray Forecasting Model with our new plan to predict the sustainable growth level in 2050.
\end{abstract}

Keywords: Sustainable Growth Level, Gray Forecasting Model

\section{Construction of Index System}

We can get the value of each city's economic status, social status and ecological environment. We define the index system's value as Q, economic status as A, social status as B, ecological environment as $\mathrm{C}$. We define the index system's equation as follows:

$$
Q=\alpha A+\beta B+\gamma C
$$

We refer to the statistical yearbook, bulletin and national and international indicators of the corresponding standards and norms to determine the threshold and upper and lower limits. Then we formulate four-level grading standards.[1]

Table 1: Four Levels

\begin{tabular}{lll}
\hline Grade & Value(Q) & Qualitative evaluation \\
\hline I & $>0.75$ & Excellent \\
II & $0.50 \sim 0.75$ & Good \\
III & $0.25 \sim 0.50$ & Moderate \\
IV & $<0.25$ & Bad \\
\hline
\end{tabular}

\section{Grey Forecasting Model}

we introduced a Gray Forecasting Model. Specific methods are as follows:[2-4] 
If a set of time series data has obvious trend, Grey Forecasting Model in the Grey System Theory can give a precise prediction even with few data. First, we get the data of 13 indicators for the previous years. Then we apply GM $(1,1)$ model, the most widely used Grey Forecasting Model, to forecast equidistantly the value of 13 indicators in the next few years until 2050. For each factor, we use the data from 2000 to 2015 (3 years as an interval, six sets of data totally), which is sufficient for GM $(1,1)$ model. The requirement is that the population increase by $50 \%$ in 2050 , so we should adjust the GM $(1,1)$ model to predict the population meeting the requirements. Then we use the 13 indicators in 2050 to calculate SGM to determine whether to meet sustainable development. This model is mainly determined by the population and SGM in 2050. The algorithm is as follows:

\section{Step 1: Data Verification and Processing}

In order to ensure the feasibility of the modeling method, it is necessary to test the known columns. We set the reference data to $x^{(0)}=\left(x^{(0)}(1), x^{(0)}(2), \cdots, x^{(0)}(6)\right)$, and calculate and verificate the ratio of the series:

$$
\lambda(k)=\frac{x^{(0)}(k-1)}{x^{(0)}(k)}, k=2,3, \cdots, n
$$

Step 2: Make an accumulation (AGO) to generate a series:

$$
\begin{aligned}
& x^{(1)}=\left(x^{(1)}(1), x^{(1)}(2), \cdots, x^{1}(6)\right) \\
& \text { Where } x^{(1)}(k)=\sum_{i=1}^{k} x^{(0)}(i)
\end{aligned}
$$

Step 3: Calculate the mean series and establish grey differential equation:

$$
\begin{gathered}
z^{(1)}(k)=0.5 x^{(1)}(k)+0.5 x^{(1)}(k-1), k=2,3, \cdots, n \\
x^{(0)}(k)+a x^{(1)}(t)=b
\end{gathered}
$$

Step 4: Calculate the predicted value:

Make

$$
u=(a, b)^{T}, Y=\left(X^{(0)}(2), X^{(0)}(3), \cdots, X^{(0)}(6)\right)^{T}, B=\left[\begin{array}{cc}
-z^{(1)}(2) & 1 \\
-z^{(1)}(3) & 1 \\
\vdots & \vdots \\
-z^{(1)}(6) & 1
\end{array}\right]
$$

$$
x^{(1)}(k+1)=\left(x^{(0)}(1)-\frac{b}{a}\right) e^{-a k}+\frac{b}{a}, k=1,2, \cdots, 5
$$




\section{City status of Zurich}

Zurich is the largest city in Switzerland, one of the safest, wealthiest and the most livable cities in Europe. Zurich is located in the north of the Alps, northwest of Lake Zurich, the mouth of the Limmat River and Lake Zurich. Urban population is 380,000. Zurich has been named one of the most livable cities in the world for many years.

Economy In Zurich, most people are engaged in secondary and tertiary sector of the economy. There are 120 banks and 70\% of the Western European stock exchanges. The employment rate is as high as $89 \%$, resulting in a high level of annual household income and per capita consumption.

Society Zurich is a historical and cultural city, so the tourism industry brings wealth and new productivity to the city .There are world-renowned prestigious schools and many schools at all levels ensure a high level of education. Zurich's infrastructure is completed. While land mixing is acceptable. The per capita housing area and infrastructure area is $402 \mathrm{~m} 2$. In short, the city is at a high standard of living.

Environment The ecological environment is also very well in Zurich , greening rate of $38 \%$, reasonable energy use, low overall pollution.

\section{New Plan for Zurich}

- Energy use: In these decades of development, Zurich consumption of resources is very large. The regeneration of resources is very important. It should focus on the development of solar energy, water resources and so on. In the course of several decades of development, the development and utilization of renewable resources will certainly make historic progress.

- Egalitarian society: For the cities of developed countries, within a few decades to solve the gap between the rich and poor is entirely possible. High-level society should maintain the current development trend. The city should focus on low-level society, and actively promote the overall development of society. All the development is based on the strength of the masses. The masses are active and the community can embark on a positive development path.

- Improve land use: The multiple use of land is critical. We can put housing, office, green area, agriculture and so on to a piece of land. Land use is increased, and it facilitates the influx of more people.

- Improve welfare system: Welfare includes housing, transportation, medical, education and so on. These aspects include the daily life of the residents, reflecting the protection of a social system. Welfare system must be developed to the details. 
- Pollution control: Zurich should primarily address water pollution. It is difficult for industrial developed cities to control industrial wastewater. There is a river next to Zurich, and it can do a good job of wastewater treatment emissions.

\section{Verification}

According to our plan above, we use our Grey Forecasting Model to forecast IS. The result is as follows:

Table 2: Population and SGM

\begin{tabular}{|c|c|c|}
\hline \multirow{2}{*}{} & \multicolumn{2}{|c|}{ IS } \\
\cline { 2 - 3 } & Now & 2050 \\
\hline Zurich & 0.7408 & 0.8523 \\
\hline
\end{tabular}

Through the data in the Table 2, we can clearly see that IS meets sustainable development by 2050.It proves our plans' correctness and effectiveness.

\section{References}

[1] Chowdhury, et al. Urban sustainability in the Third World:a review of the literature. Winnipeg: the university of Winnipeg, institute of urban studies, 1994

[2]Ying Li. Study on Optimization for Grey Forecasting Model[A]. Information Engineering Research Institute, USA.Proceedings of 2015 AASRI International Conference on Industrial Electronics and Applications(IEA 2015)[C].Information Engineering Research Institute, USA:,2015:5.

[3]Differential Hydrological Grey Model (DHGM) with self-memory function and its application to flood forecasting[J]. Science in China(Series E:Technological Sciences),2009,(04):1039-1049.

[4]STUDY ON GREY FORECASTING MODEL OF COPPER EXTRACTION RATE WITH BIOLEACHING OF PRIMARY SULFIDE ORE[J]. Acta Metallurgica Sinica (English Letters),2007,(02):117-128. 